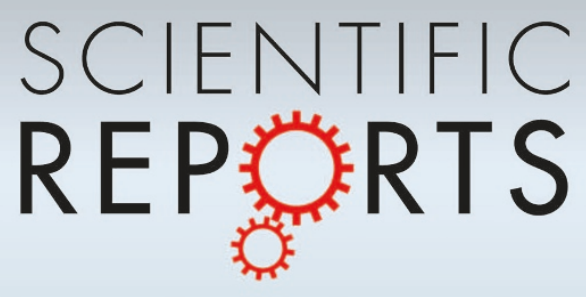

OPEN

SUBJECT AREAS:

BIOMATERIALS

MATERIALS FOR ENERGY AND

CATALYSIS

NANOSCALE MATERIALS

Received

2 September 2014

Accepted

18 December 2014

Published

15 January 2015

Correspondence and requests for materials should be addressed to S.V.K. (ketov.sergey@ wpi-aimr.tohoku.ac.jp) or H.W. (chhkwu@ust.

hk)

\section{Nanostructured Zr-Pd Metallic Glass Thin Film for Biochemical Applications}

\author{
Sergey V. Ketov' ${ }^{1}$ Xuetao Shi' ${ }^{1}$ Guoqiang Xie ${ }^{2}$, Ryotaro Kumashiro', Alexander Yu. Churyumov', \\ Andrey I. Bazlov' ${ }^{3}, \mathrm{Na} \mathrm{Chen}^{1,4}$, Yoshifumi Ishikawa ${ }^{1,5}$, Naoki Asao' , Hongkai Wu' \\ \& Dmitri V. Louzguine-Luzgin'
}

'WPI Advanced Institute for Materials Research, Tohoku University, Aoba-Ku, Sendai 980-8577, Japan, ${ }^{2}$ Institute for Materials Research, Tohoku University, Aoba-Ku, Sendai 980-8577, Japan, " National University of Science and Technology "MISiS", Moscow, Russia, ${ }^{4}$ School of Materials Science and Engineering, Tsinghua University, Beijing 100084, P. R. China, ${ }^{5}$ Department of Chemistry, Graduate School of Science, Tohoku University, Sendai 980-8578, Japan.

Zr-Pd metallic glassy thin films with a hierarchical nano-scale structure, produced by magnetron sputtering of the $\mathrm{Zr}$ and Pd powder mixture, demonstrate a unique combination of physical and biochemical properties. Thermal stability of the nano-structured glassy samples, their resistance to oxidation in dry air and phase transformation behavior are discussed in the present work. These binary alloy samples also show exceptionally high corrosion resistance and spontaneous passivation in a simulated body fluid. Experiments on the catalytic activity and biocompatibility of this nanostructured metallic glass indicate that this is a very suitable material for biochemical applications. Compared to the multicomponent alloys studied earlier this binary alloy has much simpler chemical composition, which makes preparation of the sample with defined stoichiometry easier, especially when the elements have different sputtering rates.

A $s$ a rule metallic alloy samples have a polycrystalline structure after solidification. Casting of commercial alloys even into a thin mould (with a cavity thickness of about $1 \mathrm{~mm}$ ) produces a crystalline structure which is typical for metallic materials. Following the earlier works on rapidly solidified metallic glasses, a large number of metallic glassy alloys in the different alloy systems, including bulk glassy samples, have been produced in the past two decades by using various casting processes ${ }^{1-5}$. Physical vapor deposition methods are widely used to produce metallic glassy thin films. However, even by these methods, which have one of the highest available cooling rates, thin films with amorphous structure only of the certain chemical composition can be obtained ${ }^{6}$.

Both $\mathrm{Zr}$ - and Pd-based alloys (Pd alloys being flux treated) are the best metallic glass-formers known up to date $^{7-9}$. Zr-Pd system alloys were used to produce thin metallic glassy ribbon samples ( $\sim 20 \mu \mathrm{m}$ thick) by melt spinning. The formation of a primary nanoquasicrystalline phase was observed in $\mathrm{Zr}$-rich area on heating ${ }^{10,11}$. It was shown that local atomic structure of the $\mathrm{Zr}_{65} \mathrm{Pd}_{35}$ glassy alloy is well described by taking into account the icosahedral atomic configuration ${ }^{12}$. It was also found that $\mathrm{Zr}_{\mathrm{x}} \mathrm{Pd}_{1-\mathrm{x}}(\mathrm{x}=0.59,0,63,0.67$, and 0.70$)$ amorphous alloys exhibit negative temperature coefficient of the resistivity between 10 and $300 \mathrm{~K}$. These amorphous alloys also exhibit a transition to superconductive state at low temperatures ${ }^{13}$.

Nanostructured metallic glasses or nanoglasses, consisting of irregularly placed spheroid glassy nanoparticles, represent a new and unique group of metallic materials with novel physical and chemical properties owing to their large surface area ${ }^{14}$. Metallic nano-glasses were first discovered several decades ago. Prof. Gleiter and his research group members fabricated nanoglasses by compaction of the spheroid nanoparticles produced by the inert gas condensation method ${ }^{15}$. Similar materials also can be produced by phase separation ${ }^{16,17}$. At certain conditions, individual metallic glassy particles of alloys ${ }^{18}$ and even pure metals were also obtained ${ }^{19}$. Recently, nanostructured metallic glasses were also produced by magnetron sputtering ${ }^{20}$. It was found that Au-based ${ }^{20}$ and Ti-based ${ }^{21}$ nanoglasses have good catalytic activity and biocompatibility, respectively. Also $\mathrm{Fe}_{90} \mathrm{Sc}_{10}$ nanoglassy samples, unlike ribbon samples with a homogeneous glassy structure of the same chemical composition, exhibit ferromagnetism at room temperature ${ }^{22}$.

Both $\mathrm{Zr}$ and $\mathrm{Pd}$ are suitable constituent elements for biomaterials and $\mathrm{Pd}$ is also a good catalyst for certain chemical reactions. In the present paper we investigated the Zr-Pd amorphous thin films with nano-grained structure, prepared by magnetron sputtering technique. We also present their functional properties: resistance to corrosion and oxidation as well as their catalytic activity and biocompatibility. 


\section{Results}

High catalytic activity of Pd in crystalline state is well known. Therefore, a glassy sample with high catalytic activity is presumed to contain as much $\mathrm{Pd}$ as possible. In present work, concentration of $\mathrm{Zr}$ in the sputtered films was varied from 10 to 46 at.\%. X-ray diffraction patterns of the films with different $\mathrm{Zr}$ concentration are presented in Figure 1. As one can notice, only at 46 at.\% of $\mathrm{Zr}$ (and above) the sputtered thin film becomes fully amorphous. However, further experiments on biocompatibility in the cell culturing solution revealed that, owing to the weak adhesion to the substrate, peaces of the nanoglass detached from the sample destroying osteoblasts. Therefore, in further experiments the compositions with lower palladium content were used. Also, according to the $\mathrm{Pd}-\mathrm{Zr}$ phase diagram, higher $\mathrm{Zr}$ concentration leads to deeper eutectics and more stable glasses $^{23}$. Finally, the nominal composition of 60 at. $\% \mathrm{Zr}-40$ at. \% $\mathrm{Pd}$ was chosen. Its $\mathrm{X}$-ray diffraction pattern is shown in Figure 2.

According to the results of Gaussian fitting of the first diffraction maximum ranged from 35 to 46 degrees of $2 \theta$ in the $\mathrm{X}$-ray diffraction pattern of the sputtered film (Figure 2) the center mass of the peak is located at $40.31 \pm 0.05^{\circ}$. This value is not far from $37^{\circ}$ of $2 \theta$ value obtained earlier for $\mathrm{Zr}_{70} \mathrm{Pd}_{30}$ glassy alloy prepared by melt spinning $^{10}$. The difference is owing to somewhat higher Pd content in the sputtered alloy. This element, being smaller than $\mathrm{Zr}$ in size (Goldschmidt atomic radius of $\mathrm{Zr}$ is $160 \mathrm{pm}$ while $\mathrm{Pd}$ has a size of $138 \mathrm{pm}$ ) causes a shift in the peak position ${ }^{24}$. High-resolution transmission electron microscopy and selected-area electron diffraction patterns also confirm amorphous nature of the sputtered films (Figure 2a,b).

The scanning electron microscopy (SEM) images obtained at different magnifications illustrate the granular morphology of the films (Figure $2 \mathrm{c}, \mathrm{d}$ ). The resulted composition measured by $\mathrm{x}$-ray energydispersive analysis (EDX) installed in SEM over a large area of about $10^{4} \mu \mathrm{m}^{2}$ was $62.5 \pm 0.2$ at. $\% \mathrm{Zr}$ and $37.5 \pm 0.2$ at. $\% \mathrm{Pd}$. The average composition and confidence interval values were obtained as a result of five independent measurements. The difference with the intended composition could be due to the inhomogeneous distribution of the powder particles on the target surface and the difference in the sputtering yields of each component.

$\mathrm{X}$-ray photoelectron spectroscopy (XPS) analysis of the as sputtered films surface revealed that the surface oxide film mostly consists of $\mathrm{Zr}$ atoms in $4+$ oxidation state $\left(\mathrm{Zr}^{0}\right.$ peaks are very weak in Figure 3a). It is interesting to note that $\mathrm{Pd}^{2+}$ is also present in the surface oxide (Figure $3 \mathrm{~b}$ ) which indicates that Pd on the surface is also partially oxidized.

Thermal stability and oxidation behavior of the sputtered films were investigated. Isothermal annealing of the samples was carried out in the sputtering chamber, filled with dry air, right after the films preparation (temperature range: $100-500^{\circ} \mathrm{C}(373-773 \mathrm{~K})$ for $1 \mathrm{hr}$ $(3.6 \mathrm{ks})$ ). Analysis of the X-ray diffractometry (XRD) results (Figure $3 \mathrm{c}$ ) revealed that annealing of the film in the temperature range of $100-300^{\circ} \mathrm{C}(373-573 \mathrm{~K})$ does not lead to the formation of thick surface oxide and the surface retained its metallic color. Sharp peaks appeared in the XRD pattern only after annealing at $400^{\circ} \mathrm{C}$ $(673 \mathrm{~K})$. They were found to belong to the crystalline $\mathrm{ZrO}_{2}$ (cubic symmetry, Pearson symbol cF12). The annealing at $500^{\circ} \mathrm{C}(773 \mathrm{~K})$ caused formation of monoclinic $\mathrm{mP} 12 \mathrm{ZrO}_{2}$ and $\mathrm{tP} 4 \mathrm{PdO}$. Early crystallization stage of the metallic glassy matrix in dry air starts with the formation of the weak diffraction peak at $2 \theta=40.2^{\circ}$ which may belong to the FCC Pd. Also, after annealing at $400^{\circ} \mathrm{C}(673 \mathrm{~K})$ the color of the films surface changed from metallic to violet due to the oxidation, which is in agreement with the XRD results. One can also note that the XRD peaks, which belong to the $\mathrm{ZrO}_{2}$ formed at $773 \mathrm{~K}$, are significantly broader compared to those of the $\mathrm{ZrO}_{2}$ formed at $673 \mathrm{~K}$, which implies nanocrystallization of the surface oxide at $773 \mathrm{~K}$. It should be noted here, that before in-situ annealing in the sputtering chamber for each annealing temperature an independent sample was prepared.

Corrosion behavior and chemical stability of the samples were studied in a simulated body fluid (Hank's solution, a water solution

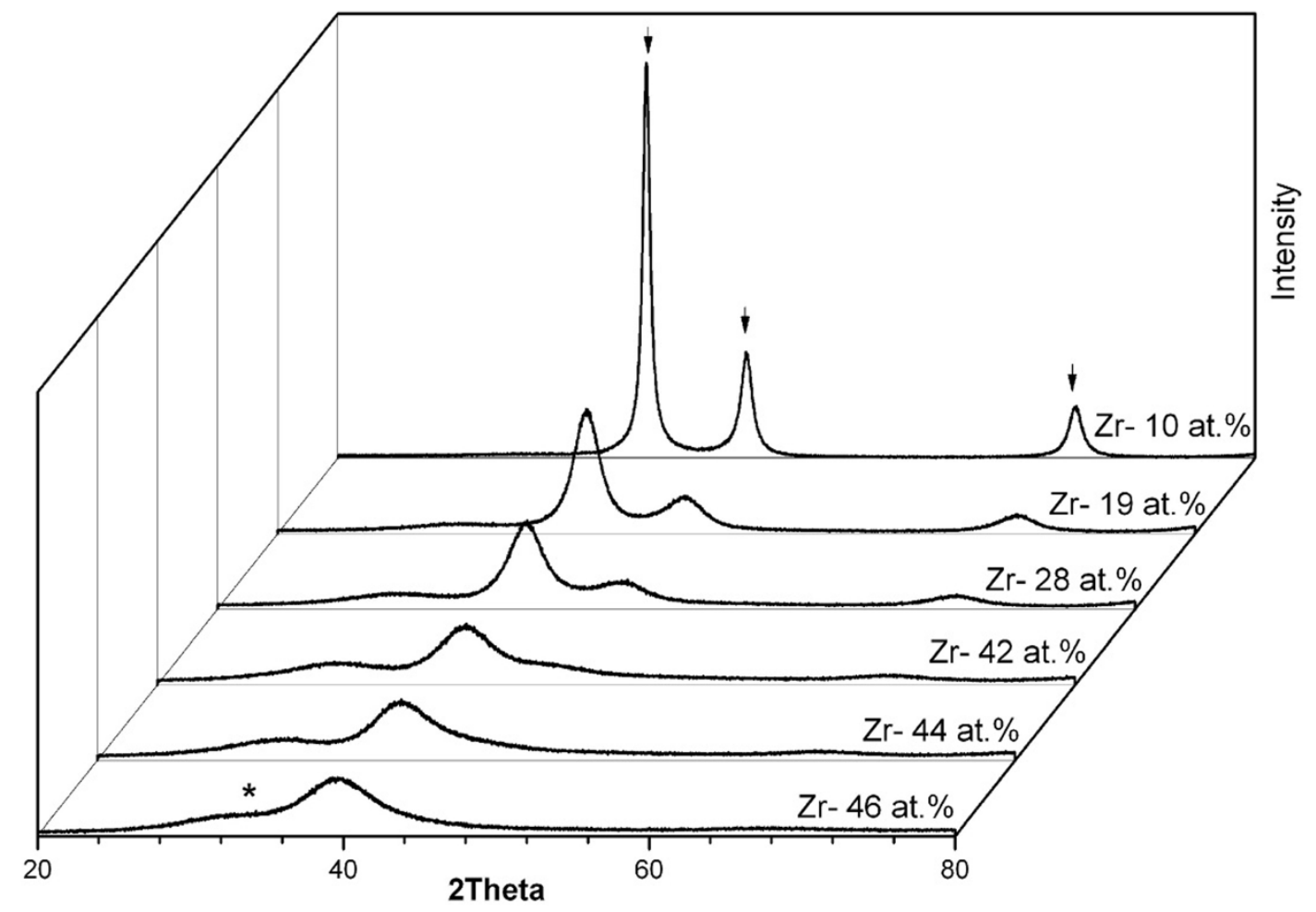

Figure $1 \mid \mathrm{X}$-ray diffraction patterns of the sputtered films with different concentration of $\mathrm{Zr}$ (Pd phase peaks are marked by arrows, while the star mark represents the broad peak from the substrate). 

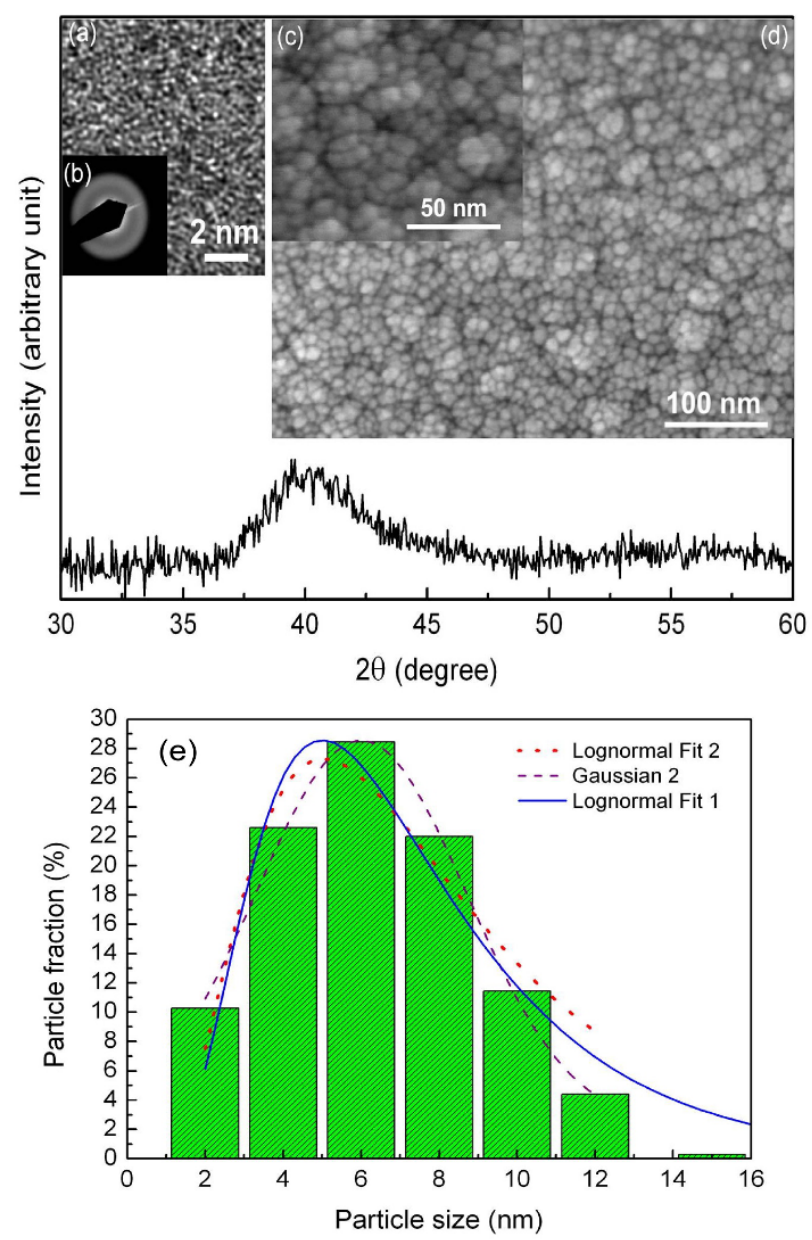

Figure $2 \mid \mathrm{X}$-ray diffraction pattern of the sputtered film with 60 at.\% of Zr. The inserts (a) high-resolution transmission electron microscopy, (b) selected-area electron diffraction pattern and (c and d) SEM images obtained in secondary electrons at different magnification and (e) particles size distribution calculated from the SEM images (c) and three fits using Lognormal (full range and up to $12 \mathrm{~nm}$ size) and Gaussian (up to $12 \mathrm{~nm}$ size) function.

of naturally occurring salt body substances). The resulted polarization curve is presented on Figure 4. Anodic polarization of the sample is characterized by fairly rapid, within $300 \mathrm{~s}$, establishment of a stationary potential (corrosion potential). As can be seen, during anodic polarization and transition to the passive state an activation peak is missing. This indicates self-passivation behavior related to the formation of a protective oxide film on the sample surface (mostly $\mathrm{ZrO}_{2}$ ), as the second component of the alloy (Pd) is significantly more stable in the corrosive environment. Weak potential fluctuations $( \pm 2-3 \mathrm{mV}$ ) in the steady-state value (around $0 \mathrm{~V}$ ) are associated with morphological features of the surface structure, and thus, the processes occurring on the alloys surface. These changes may be connected with the filling of the surface dips with the reaction products of the metal medium (here, likely, $\mathrm{ZrO}_{2}$ ), which shields the metallic surface. Throughout the wide range of the potential, corresponding to the passive region $(0-1000 \mathrm{mV})$, the alloy does not exhibit the pitting corrosion and metallic surface is preserved. The average current density in the passive state is low (for example, $3.5 \mathrm{~mA} / \mathrm{m}^{2}$ at $0.6 \mathrm{~V}$ and about $5.7 \mathrm{~mA} / \mathrm{m}^{2}$ at $1 \mathrm{~V}$ ), which is an indicator of high corrosion resistance of the $\mathrm{Zr}-\mathrm{Pd}$ film in such a corrosive biological environment.

Catalytic activity of the sputtered film was investigated in the Suzuki-coupling reaction. It was carried out after the electrolytic polishing in a solution of $900 \mathrm{ml}$ of acetic acid with $100 \mathrm{ml}$ per- chloric acid (60\%) at $15 \mathrm{~V}$ for 1 min to remove the oxide film. The reaction of 4-methylphenylboronic acid and iodobenzene was catalyzed by the material $(0.16 \mathrm{~mol} \%$ of $\mathrm{Pd})$ at $50^{\circ} \mathrm{C}$ for $36 \mathrm{~h}$ and the desired 4 -methylbiphenyl was obtained in $60 \%$ yield (Figure 5 ). This result clearly indicated that nanostructured $\mathrm{Zr}$-Pd thin film, even with 40 at.\% of Pd content, exhibits high catalytic activity for molecular transformations. The reaction products yield of about $60 \%$ is consistent with the reduced area of the sample after electrolytic polishing (see Methods section). It may be connected with the fact that some parts of the sample were etched out (Figure 6).

Osteoblast cells were chosen for biocompatibility test. These cells were deposited on the $\mathrm{Zr}$-Pd nanoglassy films, which had pure $\mathrm{Ti}$ plate as substrate, and on the pure $\mathrm{Ti}$ sheet for comparison. The standard sample had a size of $10 \times 10 \mathrm{~mm}$. The purpose of the experiment was to evaluate the material's ability to induce cellular adhesion and proliferation. After 1 day of culture it was noticed that metallic glass surface exhibits more enhanced cellular growth and live/dead staining of the cells than pure Ti (Figure $7 c, d$ ). While on the day 7 the number of alive cells on both $\mathrm{Ti}$ and nanostructured metallic glass (MG) were statistically the same, on the day 14 this number on the MG sample became $14 \%$ higher. At this point most of the cells fused their borders and formed a connected net (figure $7 \mathrm{~d}$ ). For analysis of cytoskeleton organization and cell nucleus of the osteoblasts, grown on Ti and nanoglass, they were stained by TRITCphalloidin and DAPI on Day 7 (Figure 7d). Osteoblasts formed well attached net to the surface on both $\mathrm{Ti}$ and $\mathrm{Zr}$-Pd nanoglass. Following this, the activity of alkaline phosphatase (ALP) (an early marker for osteogenesis and an important enzyme produced by osteoblasts) and the secretion of osteocalcin (late osteogenic marker and the main noncollagenous protein associated with the formation of the mineralized matrix of bone in osteoblasts) were quantitatively determined (Figure 7a,b). During the whole cultivation period the difference of ALP activity and calcium secretion between nanoglass and pure Ti was minimal and statistically insignificant.

\section{Discussion}

Physical vapor deposition methods including the magnetron sputtering technique, having high cooling rates (higher then $10^{8} \mathrm{~K} / \mathrm{s}$ ), are powerful tools to produce amorphous metallic thin films. However, even these methods do not always ensure formation of amorphous film. It may be partly connected with a relatively low deposition rate (about $110 \mathrm{pm} / \mathrm{s}$ ) which allows surface diffusion to take place during deposition. In the present work, fully amorphous films were obtained only at high enough $\mathrm{Zr}$ content. In general, the obtained results correlate with the empirical rules introduced by Inoue ${ }^{3}$. In Pd-rich side the eutectic point is located at 40.1 at. \% Zr, but only the films containing 46 at.\% $\mathrm{Zr}$ or more were in amorphous state ${ }^{23}$. The deeper eutectic point at 25 at.\% $\mathrm{Pd}$ content allowed to produce even more stable glassy film.

Thin films with an extremely fine glassy nano-granular structure (Figure 2c), as well as smooth thin films can be obtained via magnetron sputtering. Here we consider not individual glassy particles, but a material consisting of spheroid glassy particles connected by the glassy interfaces of the similar to the particle chemical composition. Fitting of the glassy particle size distribution (Figure 2e) with Lognormal distribution function (Lognormal Fit 1) gives the average size of about $6.5 \mathrm{~nm}$ (coefficient of determination $\left.\mathrm{R}^{2}=0.929\right)$. If one removes the small fraction of the largest particles the (Lognormal Fit 2) the distribution becomes less well described $\left(\mathrm{R}^{2}=0.887\right)$, while the Gaussian fit produces the best fit $\left(\mathrm{R}^{2}=0.998\right)$ with the average particles size of $6 \mathrm{~nm}$. These results indicate that real distribution is rather neither normal nor lognormal (right side part of the distribution is more steep compared to lognormal one), though both allowed to estimate the average particles size at 6-7 nm. Nevertheless, the absolute majority of the particles (99\%) have a size ranging from 2 to $12 \mathrm{~nm}$. At the same time, one can see that the sample 

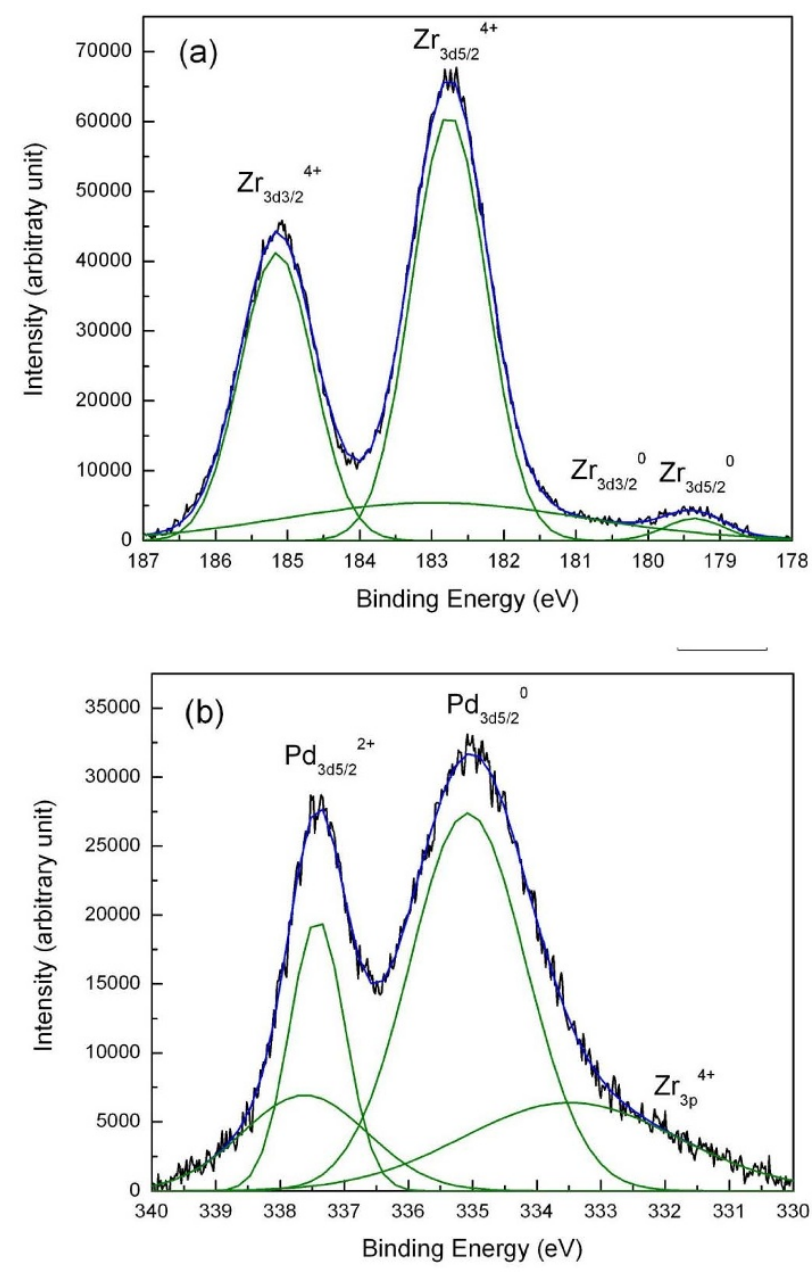

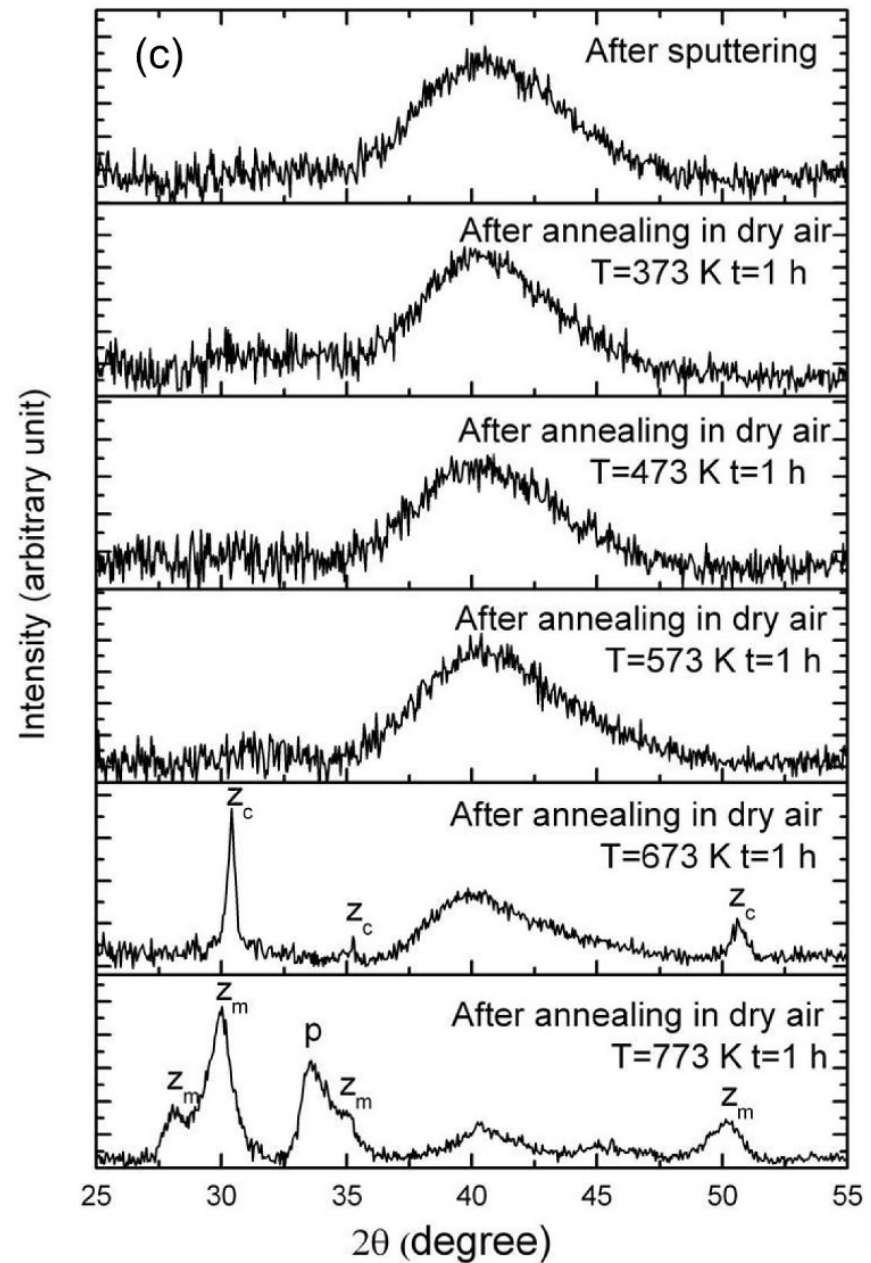

Figure $3 \mid$ XPS spectra related to (a) 3d Zr and (b) 3d Pd peaks of the as sputtered films surface layer and (c) $x$-ray diffraction patterns of the Zr-Pd thin films after annealing in dry air in the sputtering chamber. " $\mathrm{z}_{\mathrm{c}}$ " and " $\mathrm{z}_{\mathrm{m}}$ " denote the peaks of cubic and monoclinic $\mathrm{ZrO}_{2}$ phases, respectively, while "p" indicates PdO phase.

has a hierarchical structure, where small particles below $12 \mathrm{~nm}$ in size are clustered, forming larger quasi-particles or columns which are roughly about $50 \mathrm{~nm}$ in size (see Figure $2 \mathrm{c}, \mathrm{d}$ ). Such a hierarchical (fractal-type) structure is known to be suitable for biomaterials ${ }^{25}$. Ti$\mathrm{Zr}-\mathrm{Cu}-\mathrm{Pd}$ nano-structured metallic glass, having a similar structure, was recently tested as a coating for biomaterials, and found to be suitable for living cells attachment ${ }^{20}$.

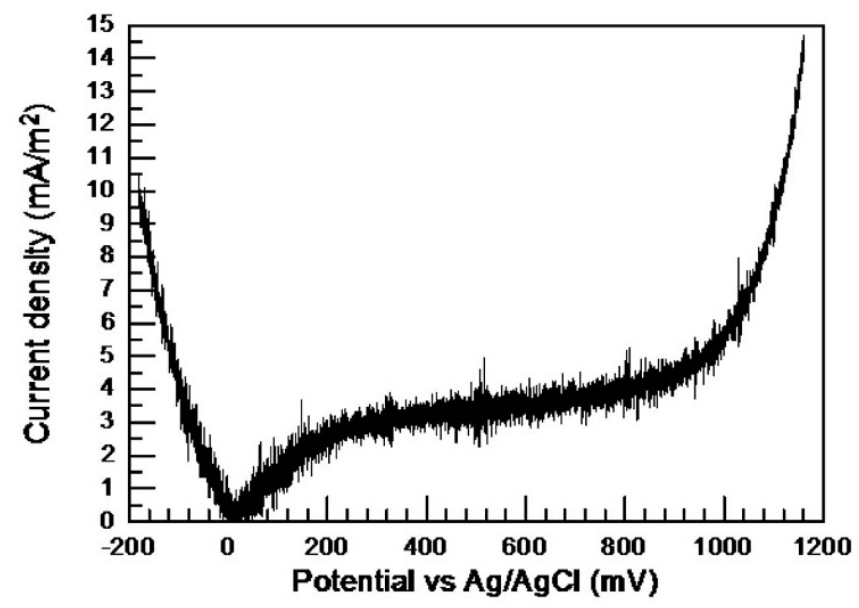

Figure $4 \mid$ Polarization curve measured in Hank's solution at $298 \mathrm{~K}$.
High corrosion resistance of the $\mathrm{Zr}$-Pd samples with extremely low current density of about $3.5 \mathrm{~mA} / \mathrm{m}^{2}$ (at $0.6 \mathrm{~V}$ ) in a simulated body fluid provides compelling evidence that this nanostructured material can be applicable as a protective coating for biomaterials. Spontaneous passivation is achieved and low current density below $6 \mathrm{~mA} / \mathrm{m}^{2}$ maintains up to a very high potential of $1 \mathrm{~V}$. This potential value is very high for metallic glasses and up to $1.1 \mathrm{~V}$ current density rise is very small (only about two times) while many other Zr-based metallic glasses studied earlier, exhibit a steep increase in the corrosion current after $0.5-0.6 \mathrm{~V}^{26}$. Obtained average current density value of about $3.5 \mathrm{~mA} / \mathrm{m}^{2}$ in the passivation region is very low for metallic alloys. Actual value per area should be even lower considering a non-smooth surface of the sample on the nanoscale (Figure $2 c, d$ ). The average current density value is lower than those values obtained for Ti-based ${ }^{27-29}, \mathrm{Zr}$-based ${ }^{30,31}$ and Fe-based ${ }^{26}$ glassy alloys as well as for crystalline alloys ${ }^{32,33}$

$\mathrm{Zr}$ as well as Ti forms a passive oxide layer. In addition, $\mathrm{Zr}$ ions show lower cell cytotoxicity than $\mathrm{Ti}^{34}$ Moreover, the corrosion current density for pure $\mathrm{Zr}$ from its potentiodynamic polarization curve in Hank's solution at $0.3 \mathrm{~V}$ is about $15.3 \mu \mathrm{A} / \mathrm{cm}^{2}$ which corresponds to $153 \mathrm{~mA} / \mathrm{m}^{2}$ and is significantly higher than that of the present nanostructured glassy alloy ${ }^{35}$

It was previously found that the addition of Pd to crystalline $\mathrm{Zr}$ decreases the passive current density. This indicates the stability of the passive film and decrease the amount of released metal ion at passive state $^{36}$. Among the six pure metals investigated for in vitro 


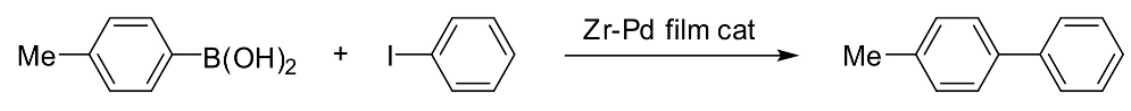

Figure 5 Equation of chemical reaction, chosen for catalytic activity measurements.

cytotoxicity together with palladium alloys, $\mathrm{Au}, \mathrm{Pd}$ and $\mathrm{Ti}$ were found to be the least cytotoxic, followed by $\mathrm{Ag}$, then $\mathrm{Ni}$, and finally $\mathrm{Cu}^{37} \cdot \mathrm{Pd}_{42.5} \mathrm{Cu}_{30} \mathrm{Ni}_{7.5} \mathrm{P}_{20}$ bulk metallic glassy samples in Hanks' solution exhibited passive current densities of the order of $10^{-2}-10^{-1}$ $\mathrm{A} / \mathrm{m}^{2}\left(10-100 \mathrm{~mA} / \mathrm{m}^{2}\right)$ in the anodic polarization curves ${ }^{38}$, which are higher than those observed in the present $\mathrm{Zr}-\mathrm{Pd}$ alloy.

Moreover, the investigation of the thermal stability and oxidation process of the nano-structured glassy samples showed that the present samples are steady against oxidation in a dry air up to $673 \mathrm{~K}$ while thermal crystallization of the glassy matrix is detected after annealing for $1 \mathrm{~h}$ at $773 \mathrm{~K}$. This is consistent with the differential scanning calorimetry studies of the crystallization process in $\mathrm{Zr}_{70} \mathrm{Pd}_{30}$ and $\mathrm{Zr}_{65} \mathrm{Pd}_{35}$ glassy alloys studied earlier, which exhibited crystallization temperature of 727 and $771 \mathrm{~K}^{10}$, respectively, at a heating rate of $0.67 \mathrm{~K} / \mathrm{s}$. Following the observed tendency, the present $\mathrm{Zr}_{62.5} \mathrm{Pd}_{37.5}$ nano-structured glassy alloy should have even higher crystallization temperature $\left(T_{x}\right)$ at such a heating rate $\left(T_{x}\right.$ is the heating rate dependent). Moreover, an increase in the crystallization temperature of the nanoglassy samples was reported recently ${ }^{39}$. At $673 \mathrm{~K}$ only $\mathrm{Zr}$ severely oxidizes forming cubic form of $\mathrm{ZrO}_{2}$ while at $773 \mathrm{~K} \mathrm{Zr}$ forms the monoclinic form of $\mathrm{ZrO}_{2}$ and even Pd starts to oxidize forming $\mathrm{PdO}$ (Figure $3 \mathrm{c}$ ). This result is in consistence with oxidation of pure Pd performed at $823 \mathrm{~K}^{40}$.

It was shown that melt-spun $\mathrm{Zr}_{70} \mathrm{Pd}_{30}$ monolithic glassy alloy samples underwent fast oxidation at $653 \mathrm{~K}$ in $30 \mathrm{~min}$ forming simultaneously two polymorphs of $\mathrm{ZrO}_{2}$ : tetragonal and monoclinic with underlying crystalline $\mathrm{Pd}^{41}$. Fast "catastrophic" oxidation of glassy $\mathrm{Zr}_{70} \mathrm{Pd}_{30}$ and $\mathrm{Zr}_{70} \mathrm{Au}_{30}$ was also observed and reported in Ref. 42. It was correlated with the formation of a lamellar structured scale consisting of the two phases, i.e. monoclinic and tetragonal $\mathrm{ZrO}_{2}$, thus allowing fast oxygen diffusion. In addition, elements like $\mathrm{Pd}$ or $\mathrm{Au}$ found to accelerate the oxygen diffusivity in $\mathrm{ZrO}_{2}$. Present results, however, indicate that nanostructured glassy films are quite stable up to $573 \mathrm{~K}$.

$\mathrm{XRD}$ analysis of the annealed films revealed the existence of an untransformed metallic glassy phase underneath $\mathrm{ZrO}_{2}$ even after annealing for $1 \mathrm{~h}$ at $673 \mathrm{~K}$ in dry air. Only at $773 \mathrm{~K}$ a minor fraction of a crystalline phase starts to form in the metallic glassy matrix. This finding allows us to anticipate that the nanostructured metallic glass is more stable against crystallization than the homogeneous one, produced by the melt spinning technique.

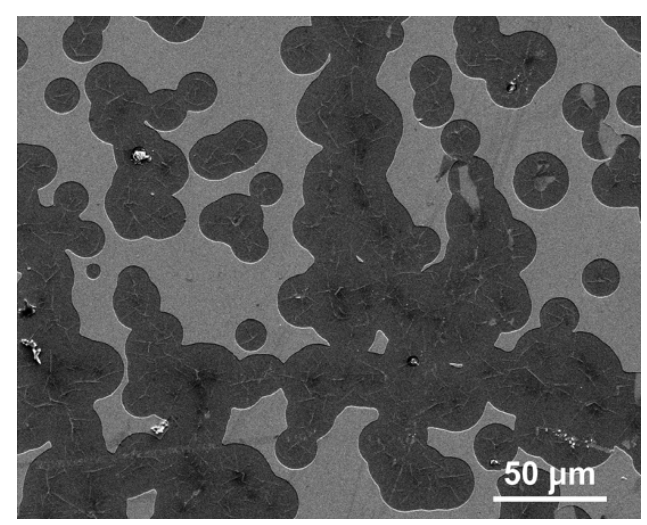

Figure 6 SEM micrograph of a partial area of the sample after electrolytic polishing (secondary electrons). Dark dray areas were etched out while light gray areas represent the remaining sample.
After electrolytic polishing of the native surface oxide the sample exhibited a moderate catalytic activity in Suzuki-coupling reaction owing to the presence of a catalyst - Pd and nanostructured surface morphology of the sample with relatively large surface area. Earlier, such a behavior was also observed in de-alloyed nanoporous $\mathrm{Pd}-\mathrm{Ni}$-P metallic glassy sample ${ }^{43}$. Pd-Si metallic glasses were also applied earlier for a catalytic reaction ${ }^{44}$.

Biocompatibility experiments also showed good results. Nanograined structure of the glassy film enhances the formation of the osteblast cells. Due to the modulated surface morphology and good corrosion resistance $\mathrm{Zr}$-Pd nanostructured glassy films showed more enhanced cell growth ability than pure Ti but slightly lower ALP activity and calcium secretion. These results are similar to that reported for $\mathrm{Ti}-\mathrm{Zr}-\mathrm{Cu}-\mathrm{Pd}$ nanoglass films ${ }^{21}$. However, a binary alloy with simpler composition was used in present work, which makes the target preparation process easier. Moreover, metallic glasses, in general, exhibit more enhanced mechanical properties and wear resistance than their crystalline counterparts ${ }^{2,3}$. The $\mathrm{Zr}$-Pd biomaterial can also be suitable as a basis for biosensors and artificial tissue engineering.

In conclusion, among a wide range of $\mathrm{Zr}$-Pd alloys studied fine nano-structured $\mathrm{Zr}_{62.5} \mathrm{Pd}_{37.5}$ metallic glassy thin film exhibits a good thermal stability versus crystallization and good resistance to oxidation in dry air up to $573-673 \mathrm{~K}$. The samples also show a very high corrosion resistance and spontaneous passivation in a simulated body fluid. Spontaneous passivation leads to low current density, which maintains up to a very high potential of $1 \mathrm{~V}$. The obtained current density of $3.5 \mathrm{~mA} / \mathrm{m}^{2}$ is a very low value for metallic alloys. After electrolytic polishing of native surface oxide the sample also exhibit catalytic activity in Suzuki-coupling reaction. Successful osteoblast cells cultivation on the nanoglassy surface indicates its good biocompatibility. Thus, this unique combination of physical and biochemical properties gives this material high application potential in biochemistry and implant engineering.

\section{Methods}

The thin $\mathrm{Zr}-\mathrm{Pd}$ films were deposited on the oxide glass substrates containing 71.3 mass $\% \mathrm{SiO}_{2}, 11$ mass\% $\mathrm{Na}_{2} \mathrm{O}, 4.5$ mass $\% \mathrm{~K}_{2} \mathrm{O}, 7$ mass $\% \mathrm{CaO}, 1.5$ mass $\% \mathrm{BaO}, 0.7$ mass $\% \mathrm{Al}_{2} \mathrm{O}_{3}, 4.2$ mass $\% \mathrm{ZnO}$ from elemental powder mixtures having purities over 99.9 mass \% by using conventional Ar-gas carrier RF magnetron sputtering technique. The details are as follows: forward power: $70 \mathrm{~W}$, the distance between the target and the sample: $70 \mathrm{~mm}$, background argon pressure: $2 \mathrm{~Pa}$, initial pressure: $2-4 \times 10^{-4} \mathrm{~Pa}$, argon flow: $10 \mathrm{ml} / \mathrm{min}$ and the average deposition rate of about $110 \mathrm{pm} / \mathrm{s}$. The average particle size of the elemental crystalline powders mixed homogeneously in the target used for sample preparation was about $10 \mu \mathrm{m}$. Different compositions were obtained by the different volume ratio of $\mathrm{Pd}$ and $\mathrm{Zr}$ powders in the mixture.

When necessary, the oxidation annealing of the samples was preformed in the same sputtering chamber in the dry mixture of nitrogen (79\%) and oxygen $(21 \%)$ to avoid any unnecessary reactions with water. Oxidation was carried out isothermally in the temperature interval $100-500^{\circ} \mathrm{C}(373-773 \mathrm{~K})$ for $1 \mathrm{hr}(3.6 \mathrm{ks})$. Each time an original sample was sputtered.

The structure and surface morphology of the thin films were investigated by X-ray diffractometry (XRD) using $C u K_{\alpha}$ radiation and scanning electron microscopy (SEM) methods, respectively. The elemental composition analysis was conducted by the energy dispersive X-ray (EDX) spectroscopy device attached to the scanning electron microscope. Transmission electron microscopy (TEM) investigations were carried out using a microscope operating at $200 \mathrm{kV}$. The samples for TEM were prepared by an ion polishing technique. In order to avoid structural damage the ionbeam energy was kept as low as $2 \mathrm{keV}$. X-ray photoelectron spectroscopy (XPS) was carried out using an apparatus equipped with Scienta MX650 X-ray source of $0.2 \mathrm{~kW}$ power having the $\mathrm{Al} \mathrm{K} \alpha(1486.7 \mathrm{eV})$ radiation.

Electrochemical measurements were performed on an electronic potentiostat, which enables continuous automatic recording of the electrochemical parameters with potential sweep rate of $0.2 \mathrm{mV} / \mathrm{s}$. The electrochemical measurements were conducted in a three-electrode cell using a platinum counter-electrode and an Ag/ $\mathrm{AgCl}$ reference electrode. The potentiodynamic polarization curves were measured at 

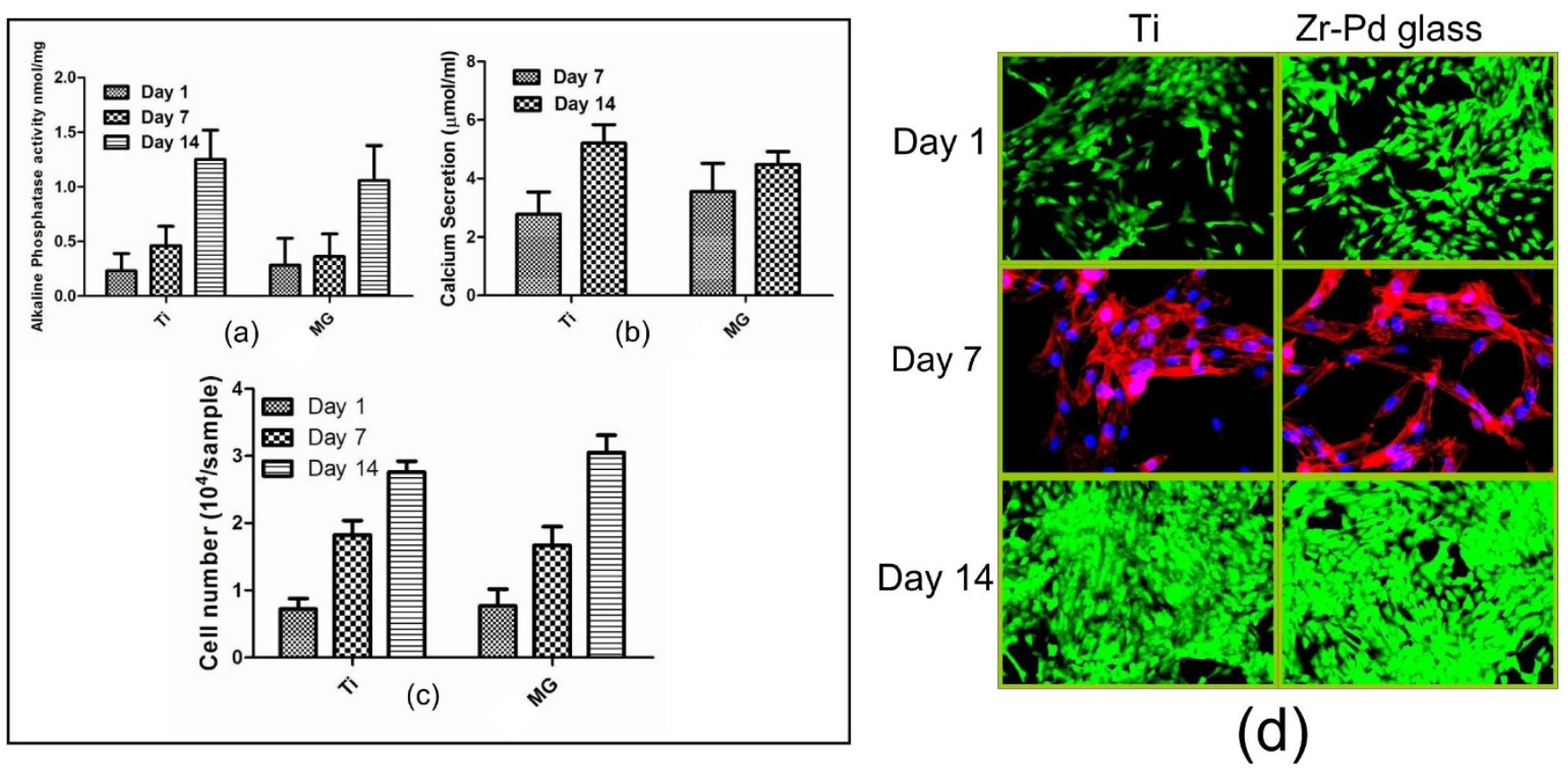

Figure 7 Alkaline phosphatase activity (a), calcium secretion (b), proliferation (c) and live/dead staining of cells (d) cultured on Ti and metallic glass (MG) (Day 1, Day 14), Day 7 - merged photos of F-actin (red) and nuclei (blue) staining of cells cultured on Ti and MG for 7 days.

$25^{\circ} \mathrm{C}(298 \mathrm{~K})$ in the Hank's solution of $8 \mathrm{NaCl}, 0.4 \mathrm{KCl}, 0.12 \mathrm{Na}_{2} \mathrm{HPO}_{4} \cdot 12 \mathrm{H}_{2} \mathrm{O}, 0.06$ $\mathrm{KH}_{2} \mathrm{PO}_{4}, 0.2 \mathrm{MgSO}_{4} \cdot 7 \mathrm{H}_{2} \mathrm{O}, 0.35 \mathrm{NaHCO}_{3}, 0.14 \mathrm{CaCl}_{2}, \mathrm{H}_{2} \mathrm{O}$ (up to 1 liter); $\mathrm{pH}=7.4$ when the open-circuit potential became almost steady ${ }^{44-46}$. Before recording the polarization curve the sample was treated at a potential of $180 \mathrm{mV}$ to remove any surface contamination.

Suzuki coupling reaction was also carried out in the presence of the $\mathrm{Zr}-\mathrm{Pd}$ material as a catalyst ${ }^{47}$. In order to clean the surface, electrolytic polishing was conducted in $900 \mathrm{ml}$ of acetic acid with the $100 \mathrm{ml}$ perchloric acid (60\%) at $10 \mathrm{~V}$ for $1 \mathrm{~min}$. After washing in pure water and methanol, the material $(0.22 \mathrm{mg}$, $0.16 \mathrm{~mol} \% \mathrm{Pd}$ ) was added to a solution of potassium hydroxide $(140 \mathrm{mg}$, $2.5 \mathrm{mmol})$ in methanol $(2 \mathrm{ml})$ at room temperature. Later 4-Methylphenylboronic acid $(102 \mathrm{mg}, 0.75 \mathrm{mmol})$ and iodobenzene $(55.7 \mathrm{ml}, 0.5 \mathrm{mmol})$ were added to the mixture, and stirred at $50^{\circ} \mathrm{C}$ for $36 \mathrm{~h}$. After cooling, Ethyl acetate (EtOAc) was added and the liquid moiety was washed in water and brined in the separation funnel. The organic layer was evaporated to leave the crude product, which was purified by silica gel column chromatography with hexane. The yield was calculated on the basis of the weight of the isolated product and depends on the surface area of the catalyst.

Osteoblasts (from American Type Culture Collection, Passage 7) were maintained in Eagle's medium (MEM) with $10 \%(\mathrm{v} / \mathrm{v})$ fetal bovine serum (FBS) and $1 \%$ penicillin/ streptomycin. Typically, $100 \mu \mathrm{l}$ cell suspensions $\left(1 \times 10^{6}\right.$ cells per $\left.\mathrm{ml}\right)$ were seeded onto the surfaces of Zr-Pd or Ti films $(1 \mathrm{~cm} \times 1 \mathrm{~cm})$ and cultured for 14 days. After 1 day, 7 days and 14 days of culture, the cell number was determined using cell counting kit-8 (Sigma-Aldrich, USA) following the manufacturer's instructions. Nuclei were counterstained with DAPI (Invitrogen, USA) and F-actin was stained with TRITCphalloidin. A Live/Dead kit (Invitrogen, USA) was used to distinguish between live and dead cells. After staining by this kit, the live and dead cells exhibited green and red color, respectively.

Alkaline phosphatase (ALP) activity of osteoblasts was performed via pNPP assay (p-nitrophenyl phosphate liquid substrate, Sigma-Aldrich, USA). Briefly, cells on the $\mathrm{Zr}$-Pd or Ti films were lysed in $0.1 \%$ Triton X-100 solutions for $10 \mathrm{~min}$ at $4^{\circ} \mathrm{C}$. After adding pNPP into the lysate, the mixed solution was incubated at $37^{\circ} \mathrm{C}$ for $30 \mathrm{~min}$, and the absorbance at $405 \mathrm{~nm}$ of the solution was measured by a plate reader (BioTex, USA). Finally, ALP activity was calculated via a formula given by the manufacturer after normalizing the cell number ${ }^{48,49}$. Osteocalcin levels of the cells on the patterns were tested using an Osteocalcin direct ELISA kit (Invitrogen, USA) following the manufacturer's instructions. The calcium secretion of cells were measured using Calcium Colorimetric assay kit (Sigma-Aldrich, US).

1. Klement, W., Willens, R. H. \& Duwez, P. Non-crystalline Structure in Solidified Gold-Silicon Alloys. Nature 187, 869-870 (1960).

2. Inoue, A. High Strength Bulk Amorphous Alloys with Low Critical Cooling Rates. Mater. Trans. JIM 36, 866 (1995).

3. Inoue, A. Stabilization of metallic supercooled liquid and bulk amorphous alloys. Acta Mater. 48, 279-306 (2000).

4. Johnson, W. L. Bulk Glass-Forming Metallic Alloys: Science and Technology. MRS Bull. 24, 42-56 (1999).
5. Egami, T. Nano-glass Mechanism of Bulk Metallic Glass Formation. Mater. Trans. 43, 510-517 (2002).

6. Louzguine-Luzgin, D. V., Ketov, S. V., Orava, J. \& Mizukami, S. Optically transparent magnetic and electrically conductive Fe-Cr-Zr ultra-thin films. Phys. Status Solidi A 211, 999-1004 (2014).

7. Nishiyama, N. \& Inoue, A. Glass-Forming Ability of Bulk $\mathrm{Pd}_{40} \mathrm{Ni}_{10} \mathrm{Cu}_{30} \mathrm{P}_{20}$ Alloy. Mater Trans JIM 37, 1531-1539 (1996).

8. Lu, I.-R., Wilde, G., Görler, G. P. \& Willnecker, R. Thermodynamic properties of Pd-based glass-forming alloys. J. Non-Cryst. Solids 250-252, 577-581 (1999).

9. Chen, N. et al. Flux-induced structural modification and phase transformations in a $\mathrm{Pd}_{40} \mathrm{Ni}_{40} \mathrm{Si}_{4} \mathrm{P}_{16}$ bulk-glassy alloy. Acta Mater. 58, 5886-5897 (2010).

10. Murty, B. S., Ping, D. H. \& Hono, K. Nanoquasicrystallization of binary Zr-Pd metallic glasses. Appl.Phys. Let. 77, 1102-1104 (2000).

11. Kramer, M. J. et al. Devitrification studies of Zr-Pd and Zr-Pd-Cu metallic glasses. J. of Non-Cryst. Solids 317, 62-70 (2003).

12. Takahara, Y. \& Narita, N. Local Electronic Structures and Chemical Bonds in ZrBased Metallic Glasses. Mater. Trans. 45, 1172-1176 (2004).

13. Gruzalski, G. R., Gerber, J. A. \& Sellmyer, D. J. Electronic properties and superconductivity of Zr-Pd glasses. Phys. Rev. B 19, 3469-3475 (1979).

14. Gleiter, H., Schimmel, Th \& Hahn, H. Nanostructured solids - From nanoglasses to quantum transistors. Nano Today 9, 17-68 (2014).

15. Fang, J. X. et al. Atomic structure and structural stability of $\mathrm{Sc}_{75} \mathrm{Fe}_{25}$ nanoglasses. Nano Lett. 12, 458-463 (2012).

16. He, J. H., Sheng, H. W., Schilling, P. J., Chien, C.-L. \& Ma, E. Amorphous Structures in the Immiscible Ag-Ni System. Phys. Rev. Let. 86, 2826 (2001).

17. Banerjee, R., Puthucode, A., Bose, S. \& Ayyub, P. Nanoscale phase separation in amorphous immiscible copper-niobium alloy thin films. Appl. Phys. Let. 90, 021904 (2007).

18. Jing, J., Kramer, A., Birringer, R., Gleiter, H. \& Gonser, U. Modified atomic structure in a PdFeSi nanoglass. A Mössbauer study. J. Non-Cryst. Solids 113 167-170 (1989).

19. Kim, Y.-W., Lin, H.-M. \& Kelly, T. F. Amorphous solidification of pure metals in submicron spheres, Acta Metall. 37, 247-255 (1989).

20. Chen, N. et al. Formation and properties of Au-based nanograined metallic glasses Acta Mater. 59, 6433-6440 (2011).

21. Chen, N. et al. A novel Ti-based nanoglass composite with submicronnanometer-sized hierarchical structures to modulate osteoblast behaviors. J. Mater. Chem. B 1, 2568-2574 (2013).

22. Witte, R. et al. Evidence for enhanced ferromagnetism in an iron-based nanoglass. Appl. Phys. Let. 103, 073106 (2013).

23. Okamoto, H. Pd-Zr (Palladium-Zirconium). J. of Phase Equilibria and Diffusion 30, 413-414 (2009).

24. Gale, W. F. \& Totemeier, T. C. Smithells Metals Reference Book [8-th ed], (Elsevier Butterworth-Heinemann Ltd., Oxford, 2004).

25. Tan, J. \& Saltzman, W. M. Biomaterials with hierarchically defined micro- and nanoscale structure. Biomaterials 25, 3593-3601 (2004).

26. Wang, Y. B., Li, H. F., Zheng, Y. F. \& Li, M. Corrosion performances in simulated body fluids and cytotoxicity evaluation of Fe-based bulk metallic glasses. Mater. Sci. and Eng. C 32, 599 (2012). 
27. Oak, J. J., Louzguine-Luzgin, D. V. \& Inoue, A. Fabrication of Ni-free Ti-based bulk-metallic glassy alloy having potential for application as biomaterial, and investigation of its mechanical properties, corrosion, and crystallization behavior. J. of Mater. Res. 22, 1346-1353 (2007).

28. Qin, F. et al. Corrosion Behavior of a Ti-Based Bulk Metallic Glass and Its Crystalline Alloys. Mater. Trans. 48, 1855-1858 (2007).

29. Oak, J. J., Louzguine-Luzgin, D. V. \& Inoue, A. Investigation of glass-forming ability, deformation and corrosion behavior of Ni-free Ti-based BMG alloys designed for application as dental implants. Mater. Sci. and Eng.: C 29, 322-330 (2009).

30. Wang, Y. B., Zheng, Y. F., Wei, S. C. \& Li, M. In vitro study on Zr-based bulk metallic glasses as potential biomaterials. J. of Biomed. Mater. Res. B: Appl. Biomater. 96B, 34-46 (2011)

31. Qiu, C. L. et al. A novel Ni-free Zr-based bulk metallic glass with enhanced plasticity and good biocompatibility. Scripta Mater. 55, 605-608 (2006).

32. Lavos-Valereto, I. C., Wolynec, S., Ramires, I., Guastaldi, A. C. \& Costa, I. Electrochemical impedance spectroscopy characterization of passive film formed on implant Ti-6AI-7Nb alloy in Hank's solution. J. of Mater. Sci.: Mater. in Medic. 15, 55-59 (2004)

33. Sridhar, T. M., Kamachi, M. U. \& Subbaiyan, M. Preparation and characterisation of electrophoretically deposited hydroxyapatite coatings on type 316L stainless steel. Corrosion Sci. 45, 237-252 (2003).

34. Yamamoto, A., Honma, R. \& Sumita, M. Cytotoxicity evaluation of 43 metal salts using murine fibroblasts and osteoblastic cells. J. Biomed. Mater. Res. 39, 331-340 (1998).

35. Zhou, F. Y et al. Microstructure, corrosion behavior and cytotoxicity of $\mathrm{Zr}-\mathrm{Nb}$ alloys for biomedical application. Mater. Sci. and Eng. C 32, 851-856 (2012).

36. Tsutsumi, Y., Takano, Y., Doi, H., Noda, K. \& Hanawa, T. Corrosion behavior of $\mathrm{Zr}-\mathrm{Pt}$ and Zr-Pd alloys for biomaterials in simulated body fluid. Paper presented at 214th Meeting of the Electrochemical Society. Fall Meeting of The Electrochemical Society of Japan PRiME, Honolulu, The Electrochemical Society, (2008) October $12-17$.

37. Craig, R. G. \& Hanks, C. T. Cytotoxicity of experimental casting alloys evaluated by cell culture tests. J. Dent. Res. 69, 1539-1542 (1990).

38. Qin, F., Xie, G., Wada, T., Zhu, S. \& Dan, Z. Electrochemical Properties of Porous Pd-Based Bulk Metallic Glasses. Mater. Trans. 54, 1347-1350 (2013).

39. Wang, J. Q., Chen, N., Glendenning, T. W., Louzguine, D. V. \& Perepezko, J. H. The thermal behavior of a nano-grained Au-based glass. Paper presented at 20th International Symposium on Metastable and Nano Materials (ISMANAM-2013). Book of Abstracts. Torino, Italy, 2013, June 30-July 5.

40. Pilloy, Th., Zimmermann, R., Steiner, P. \& Hufner, S. The electronic structure of PdO found by photoemission (UPS and XPS) and inverse photoemission (BIS). J. Phys.: Condens. Matter 9, 3987-3999 (1997).

41. Mondal, K., Chatterjee, U. K. \& Murty, B. S. Oxidation behavior of amorphous and nanoquasicrystalline $\mathrm{Zr}-\mathrm{Pd}$ and $\mathrm{Zr}-\mathrm{Pt}$ alloys. J. of Alloys and Compd. 460, 172-181 (2008).

42. Köster, U. \& Jastrow, L. Oxidation of Zr-based metallic glasses and nanocrystalline alloys. Mater. Sci. Eng. A 449-451, 57-62 (2007).

43. Tanaka, S. et al. A nanostructured skeleton catalyst: Suzuki-coupling with a reusable and sustainable nanoporous metallic glass Pd-catalys. Chem. Commun. 47, 5985-5987 (2011).
44. Molnár, Á., Smith, G. V. \& Bartók, M. Hydrogenation of (+)-Apopinene over PdSi and Pd-Ge Glasses. J. of Catalysis 101, 540-544 (1986).

45. de Assis, S. L., Wolynec, S. \& Costa, I. Corrosion characterization of titanium alloys by electrochemical techniques. Electrochimica Acta 51, 1815-1819 (2006)

46. ASTM Standard G59-97 "Standard Test Method for Conducting Potentiodynamic Polarization Resistance Measurements" Annual Book of ASTM Standards [Volume 03.02] (ASTM International, West Conshohocken, PA, 2014).

47. Miyaura, N., Suzuki, A. Stereoselective synthesis of arylated (E)-alkenes by the reaction of alk-1-enylboranes with aryl halides in the presence of palladium catalyst. Chem. Comm. 19, 866-867 (1979).

48. Shi, X. T. et al. Microsphere-based drug releasing scaffolds for inducing osteogenesis of human mesenchymal stem cells in vitro. Eur. J. Pharm. Sci. 39, 59-67 (2010).

49. Shi, X. T. et al. In-vitro osteogenesis of synovium stem cells induced by controlled release of bisphosphate additives from microspherical mesoporous silica composite. Biomaterials 30, 3996-4005 (2009).

\section{Acknowledgments}

This work was supported by World Premier International Research Center Initiative (WPI), MEXT, Japan and by the Ministry of Education and Science of the Russian Federation in the framework of Increase Competitiveness Program of NUST «MISiS» (№ K2-2014-013)

\section{Author contributions}

S.V.K. and D.V.L.-L. wrote and corrected the manuscript text and figures, X.T. Sh. and H.W. prepared fig. 6 and wrote the biocompatibility part, G.X. and R.K. prepared fig. 3 and wrote XPS measurement part, A. Yu. Ch., A.I.B. and N. Ch. prepared fig. 4 and wrote corrosion testing part, Y.I. and N.A. prepared fig. 5 and wrote catalytic activity part. All authors reviewed the manuscript.

\section{Additional information}

Competing financial interests: The authors declare no competing financial interests.

How to cite this article: Ketov, S.V. et al. Nanostructured Zr-Pd Metallic Glass Thin Film for Biochemical Applications. Sci. Rep. 5, 7799; DOI:10.1038/srep07799 (2015).

This work is licensed under a Creative Commons Attribution-NonCommercialShareAlike 4.0 International License. The images or other third party material in this article are included in the article's Creative Commons license, unless indicated otherwise in the credit line; if the material is not included under the Creative Commons license, users will need to obtain permission from the license holder in order to reproduce the material. To view a copy of this license, visit http:// creativecommons.org/licenses/by-nc-sa/4.0/ 